\title{
TIPOLOGIA DOS DEPÓSITOS DIAMANTÍFEROS DA SERRA DO ESPINHAÇO E ADJACÊNCIAS EM MINAS GERAIS: UMA SÍNTESE DOS CONHECIMENTOS
}

\author{
MARIO LUIZ DE SÁ CARNEIRO CHAVES ${ }^{1} \&$ JOACHIM KARFUNKEL ${ }^{1}$
}

\begin{abstract}
RESUMO A Província Diamantífera da Serra do Espinhaço, foi tomada como modelo para a definição de variados tipos de depósitos secundários onde o diamante aparece, descritos em ordem cronológica. Formados a partir de fontes primárias ainda desconhecidas, no Espinhaço Meridional os depósitos mais antigos são do tipo paleoplaceres, da Formação Sopa-Brumadinho, na região de Diamantina (Supergrupo Espinhaço, Paleo/ Mesoproterozóico). Potentes níveis conglomeráticos apresentando ambientes de sedimentação diversos, são conhecidos em associação ao desenvolvimento do "Rifte Espinhaço". Em Grão Mogol (Espinhaço Central), os conglomerados diamantíferos da Formação Grão Mogol são pouco espessos, apresentando-se estratigraficamente superiores aos da região de Diamantina. De idade neoproterozóica, os depósitos glaciogênicos do Grupo Macaúbas (Supergrupo São Francisco), são localmente diamantíferos nas circunvizinhanças do Espinhaço Meridional. Os depósitos fanerozóicos mais antigos são aqueles relacionados ao Conglomerado Abaeté (Grupo Areado), de idade cocretácica, representando sedimentos fluviais, derivados do soerguimento da Serra do Espinhaço no Mesozóico. Esse conglomerado é recoberto por lateritas, provavelmente também diamantíferas, desenvolvidas durante o Terciário. Depósitos fanglomeráticos de borda serrana, tanto no Espinhaço s.s., como na Serra do Cabral, formaram-se no Terciário Superior/ Pleistoceno às custas dos conglomerados pré-cambrianos e/ou sedimentos derivados. Em áreas intra-serranas, depósitos coluvionares pouco espessos do Pleistoceno Superior/Holoceno, também possuem diamantes nas proximidades de rochas e sedimentos mineralizados mais antigos. Cascalhos aluvionares diamantíferos tardi-pleistocênicos a holocênicos, constituem os depósitos historicamente mais abrangidos pela mineração, aparecendo em terraços altos, planícies aluvionares e nas calhas atuais dos rios modernos.
\end{abstract}

Palavras-chlave: diamantes, depósitos minerais, geologia econômica, Serra do Espinhaço.

\begin{abstract}
TYPES OF DIAMOND-BEARING DEPOSITS IN THE ESPINHAÇO RANGE (MINAS GERAIS): A SYNTHESIS The Diamondiferous Espinhaço Range Province is taken as a model for the definition of several types of secondary deposits with diamonds, discussed in chronological sequence. The oldest deposits are paleoplacers originated from an unknown primary magmatic source. They belong to the SopaBrumadinho Formation in the Diamantina region (Espinhaço Supergroup, Paleo- to Mesoproterozoic). These thick conglomeratic lenses, which formed in different sedimentary environments, are associated with the development of the "Espinhaço Rift". In Grão Mogol (Central Espinhaço) the conglomerates of the Grio Mogol Formation are younger than those of the Diamatina region. The glaciogenic deposits of the Neoproterozoic Macaúbas Group (São Francisco Supergroup) are locally diamondiferous. The oldest Phanerozoic occurrences are related to the Eocretaceous Abaeté conglomerate (Areado Group) of fluvial nature, originated during the uplift of the Espinhaço Range at Mesozoic time. This conglomerate is covered by Tertiary laterites which are probably diamondiferous too. Fanglomerates in the vicinity of the range resulted from the reworking of Precambrian conglomerates during the Upper Tertiary/Pleistocene. In intra-range areas thin colluvial deposits of Pleistocene/Holocene age are mineralized, when located near older diamondiferous sediments. Late Pleistocene to Holocene alluvial gravel are historically the most important source for diamond explotation. They occur in high terraces, in alluvial flats and in recent river gravel.
\end{abstract}

Keywords: diamonds, mineral deposits, economic geology, Espinhaço Range.

INTRODUÇÃO A Serra do Espinhaço constitui uma província diamantífera com diversos distritos e campos mineralizados, nos estados de Minas Gerais e Bahia. Em Minas Gerais, destacam-se os distritos de Diamantina e de Grão Mogol, responsáveis historicamente pela maior parcela (@50\%) de todos os diamantes já produzidos no país. Ainda atualmente, grande parte da economia regional é dependente dessa produção, apesar de que, nos últimos dez anos, as taxas venham sofrendo reduções de forma rápida. A proveniência dos diamantes lavrados mecanicamente ou por meio de garimpagem, é bastante variada. Algumas tentativas de agrupar tais depósitos foram propostas anteriormente (Moraes \& Guimarães 1930, Moraes 1934, Pflug 1965, Chaves \& Uhlein 1991, Chaves et al. 1993), ainda que não tenham envolvido a totalidade dos mesmos.

Nos últimos anos, diversos estudos visando diferentes áreas geográficas foram realizados (Chaves 1997, Chaves \& Karfunkel 1997, Chaves et al. 1998a, 1999), assim como no- vas idéias e revisões a respeito da evolução geológica e correlações estratigráficas regionais têm sido propostas (Uhlein $e t$ al. 1995, Dussin \& Dussin 1995, Schobbenhaus 1993, Fleischer 1998, Uhlein \& Chaves 2001). A partir dessas contribuições, apresenta-se uma relação abrangente para incluir depósitos de origem sedimentar, com idades distribuídas desde o Paleo/Mesoproterozóico até o Recente. Rochas-fonte primárias, como kimberlitos e/ou lamproítos, são até hoje desconhecidas na região.

DEPÓSITOS DIAMANTÍFEROS Os diferentes tipos de depósitos diamantíferos que ocorrem na Serra do Espinhaço e zonas adjacentes em Minas Gerais, distribuídos sobre uma imensa região (Fig. 1), serão descritos segundo suas idades de sedimentação, tendo em vista que rochas-fonte primárias indiscutivelmente mineralizadas ainda não tenham sido descritas. Tais depósitos de natureza sedimentar possuem idades distribuídas desde o Paleo/Mesoproterozóico até o Recente. Embora 


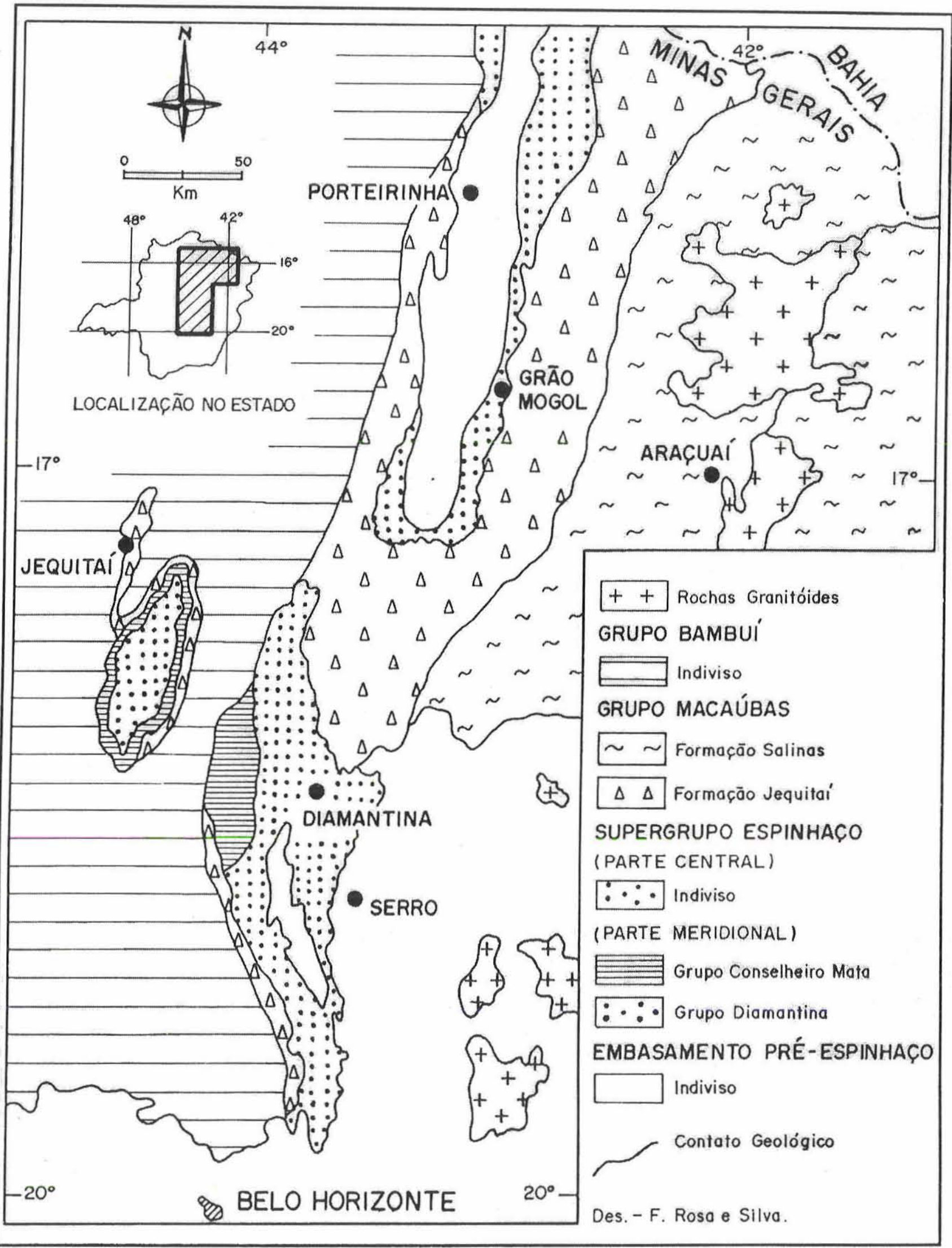

Figura I - Mapa geológico simplificado da Serra do Espinhaço em suas porções Meridional e Central em Minas Gerais, mostrando as principais áreas referidas no trabalho (modificado de Chaves 1997). 
algumas dessas idades não sejam absolutas, a grande maioria delas pode ser considerada bem estabelecida por datações radiométricas (caso das seqüências pré-cambrianas) ou por fósseis e/ou inferências acerca de grandes eventos climáticos regionais e mundiais (caso das seqüências fanerozóicas).

Na porção basal do Supergrupo Espinhaço, na região de Diamantina, as formações Bandeirinha e São João da Chapada são integrantes do Grupo Diamantina (Paleo- a Mesoproterozóico). Anteriormente, a Formação Bandeirinha era considerada como a seqüência de topo do Supergrupo Rio Paraúna, sendo daí desmembrada a partir de sugestões de Dossin et al. (1990) e detalhamentos de campo conforme Silva (1995) e Martins-Neto (1998). Em ambas as unidades ocorre, com espessura irregular $(<3 \mathrm{~m})$ e de modo descontínuo, um metaconglomerado brechóide muito endurecido, cuja origem está relacionada aos primeiros estágios de estruturação do Rifte Espinhaço (Dussin \& Dussin 1995, Silva 1995, Uhlein et al. 1995). Chaves (1997), em sua modelagem de evolução geológica do diamante na região, sugeriu que tais rochas sejam diamantíferas, ainda que faltem evidências mais diretas a respeito.

\section{Supergrupo Espinhaço: Formação Sopa-Brumadinho A} Formação Sopa-Brumadinho (Pflug 1968, Schöll \& Fogaça 1979), integrante do Supergrupo Espinhaço, compreende diversas litologias, como filitos, quartzitos e conglomerados de variados tipos. Algumas dessas últimas rochas são conhecidas como diamantíferas desde meados do século passado, quando Burton (1869, in Chaves 1997), descreveu o "itacolomito branco e vermelho, granular e quartzoso" como a rocha fonte do diamante na região. Moraes \& Guimarães (1930) designaram tais rochas de "Conglomerado Sopa", como serão referenciadas neste trabalho, apesar de apresentarem um metamorfismo de baixo grau. O Conglomerado Sopa (sensu lato) é a principal rocha contendo diamantes no âmbito desta formação, embora a mesma possua outros tipos litológicos também mineralizados, relacionados a seguir, que afloram de modo característico nos quatro principais campos diamantíferos do Distrito de Diamantina: São João da Chapada, Sopa-Guinda, Datas e Extração.

METACONGLOMERADOS (POLI- E MONOMÍTICOS) Pflug (1965) reconheceu três tipos distintos de conglomerados contendo diamantes na região de Diamantina, todos aparecendo principalmente em formas lenticulares.

(i) A primeira e mais importante corresponde ao Conglomerado Sopa conforme as descrições originais de Moraes \& Guimarães (1930), que constitui uma rocha polimítica, formada por clastos de diâmetros alcançando até $1 \mathrm{~m}$, localmente predominando os angulosos, localmente os arredondados. Tais clastos podem ser tanto de rochas intra-bacinais, como quartzitos, metapelitos, metavulcânicas e metaconglomerados, como de rochas externas à bacia de sedimentação, como xistos, itabiritos e quartzos de veio. A matriz também se modifica de acordo com os diferentes sítios de afloramento, desde metapelítica em Extração até metarenosa grossa em SopaGuinda, assim como a espessura dos depósitos (50-100? $\mathrm{m} \mathrm{em}$ Extração e 3-12m em Sopa-Guinda/Datas, conforme Tabela 1) e os teores médios em diamantes. Segundo Chaves (1997), estes últimos são sempre baixos, variando entre $0,01 \mathrm{ct} / \mathrm{m}^{3}$ (campo de Sopa-Guinda) até próximo de $0,1 \mathrm{ct} / \mathrm{m}^{3}$ (campos de São
João da Chapada, Datas e Extração). Na Tabela 2, apresentase os principais minerais pesados encontrados no Conglomerado Sopa, ressaltando-se a completa ausência de indicadores de fontes primárias, embora as análises tenham chegado ao nível de encontrar micro-diamantes em um dos depósitos (Lavra Datas de Cima, nas proximidades da cidade de Datas).

(ii) Os conglomerados "monomíticos", localmente diamantíferos, possuem um amplo predomínio de clastos de quartzo leitoso, embora clastos de quartzito sejam observados de modo esporádico (Pflug 1965). Nos campos de Extração e Datas, tais rochas aparecem associadas aos conglomerados do tipo-Sopa, enquanto em muitos locais fora destes e dos outros campos, ocorrem isoladamente em diversas porções estratigráficas da formação, em todos os casos com espessuras inferiores a $2 \mathrm{~m}$. Dados econômicos a respeito destas rochas são pouco conhecidos. Enquanto o Conglomerado Sopa típico (polimítico) tem sua origem normalmente atribuída a depósitos de leques aluviais (Garcia \& Uhlein 1987, Uhlein 1991, Martins-Neto 1998), os conglomerados monomíticos, provavelmente, possuem origem fluvial.

(iii) O terceiro tipo de conglomerado corresponde ao que Draper (1920) e Moraes \& Guimarães (1930) chamaram de "breccias eruptivas", enquanto Kerr et al. (1941) as consideraram de origem sedimentar. Da mesma forma, Pflug (1965) e Fogaça \& Almeida-Abreu (1982) admitiram a natureza sedimentar das "brechas quartzíticas", embora Chaves. (1997) tenha designado esses sedimentos de "conglomerados brechóides”. Tal litologia aflora de modo característico em uma faixa quase contínua desde o campo de Sopa-Guinda até o campo de São João da Chapada. Fogaça \& Almeida-Abreu (1982) integraram tal litologia ao então proposto Membro Campo Sampaio, no topo da Formação Sopa-Brumadinho, levantando em detalhe vários dos seus sítios de ocorrência. Os corpos desta rocha são tabulares com espessuras máximas de $10 \mathrm{~m}$, com clastos de quartzito vermelho, subangulosos a subarredondados (diâmetro máximo de $20 \mathrm{~cm}$ ) em matriz metapelítica branca, possuindo ambiente deposicional alvo de muitas controvérsias (discussões em Garcia \& Uhlein 1987). Na área de Sopa-Guinda, seus teores médios em diamantes são ínfimos $\left(<0,01 \mathrm{ct} / \mathrm{m}^{3}\right)$, enquanto na área de São João da Chapada podem alcançar até $0,1 \mathrm{ct} / \mathrm{m}^{3}$, onde se verificam os importantes depósitos de Pagão, Campo Sampaio, Jo-bô e Campo de São Domingos .

QUARTZITOS CONGLOMERÁTICOS No âmbito da Formação Sopa-Brumadinho, os quartzitos conglomeráticos compreendem uma da mais abundantes litologias, incluindo desde conglomerados finos até quartzitos grossos com seixos esparsos. A possível presença de diamantes em tais rochas pode ser inferida a partir da existência de depósitos, tanto coluvionares como aluvionares, associados a faixas de exposição das mesmas, em diversos locais onde não ocorrem os outros tipos conglomeráticos, como verificado nas proximidades de Mendanha, $25 \mathrm{~km}$ a nordeste de Diamantina. Tais litologias apresentam diversos aspectos que permitem considerá-las como fluviais. Turner \& Minter (1985), demonstraram em estudos realizados em depósitos semelhantes da Suazilândia (África Sul-Oriental), que os arenitos conglomeráticos podem conter reservas importantes de mineralização diamantífera, entretanto estudos específicos sobre o assunto na região do 
Tabela I - Principais aspectos dos conglomerados diamantíferos da Formação Sopa-Brumadinho nos diversos campos do Distrito de Diamantina (modificada de Chaves \& Svisero 1993).

\begin{tabular}{|c|c|c|c|c|c|}
\hline \multicolumn{2}{|c|}{$\begin{array}{c}\text { Características dos } \\
\text { conglomerados }\end{array}$} & Sopa-Guinda & Campo Sampaio & Datas & Extração \\
\hline \multicolumn{2}{|c|}{ Forma dos corpos } & lenticular & acanalada & lenticular & lenticular/acanalada \\
\hline \multicolumn{2}{|c|}{ Espessura máxima } & $12 \mathrm{~m}$ & $10 \mathrm{~m}$ & $25 \mathrm{~m}$ & $100 \mathrm{~m}(?)$ \\
\hline \multirow{5}{*}{ Clastos } & Classificação & polimítico & polimálico & polimítico & polimítico \\
\hline & Selecionamento & $\begin{array}{l}\text { mal } \\
\text { selecionado }\end{array}$ & $\begin{array}{l}\text { mal } \\
\text { selecionado }\end{array}$ & $\begin{array}{l}\text { mal } \\
\text { selecionado }\end{array}$ & $\begin{array}{l}\text { mal } \\
\text { selecionado }\end{array}$ \\
\hline & Tamanho máximo & $0,8 \mathrm{~m}$ & $0.5 \mathrm{~m}$ & $0.6 \mathrm{~m}$ & $1,0 \mathrm{~m}$ \\
\hline & Suporte & clasto-sustentado & clasto-sustentido & clasto-sustentado & clasto-sustentado \\
\hline & Arredondamento & subarredondados & subangulosos & subarredondados & subangulosos \\
\hline \multicolumn{2}{|c|}{ Matriz predominante } & arenosa & argilosa & areno-argilosa & argilosa \\
\hline
\end{tabular}

Tabela 2 - Freqüência dos minerais pesados encontrados nos conglomerados diamantíferos da Serra do Espinhaço (modificada de Chaves 1997). Percentuais utilizados: $x x x x=70-100 \%, x x=20-70 \%, x x=1-20 \%, x=<1 \%$. Minerais, I-anatásio, I-cianita, 3diamante, 4-hematita, 5-magnetita, 6-monazita, 7-ouro, 8-pirita, 9-rutilo, 10-turmalina, I1-xenotímio, 12-zircão. (*) Conglomerados tipo-Sopa, (**) Brechas conglomeráticas, (***) Conglomerados em Grão Mogol.

\begin{tabular}{|c|c|c|c|c|c|c|c|c|c|c|c|c|}
\hline Depósitos & 1 & 2 & 3 & 4 & 5 & 6 & 7 & 8 & 9 & 10 & 11 & 12 \\
\hline Lavrinha (*) & $\mathrm{xxx}$ & - & - & $\mathrm{xxxx}$ & $\mathrm{xxx}$ & - & - & - & $\mathrm{x}$ & $\mathrm{xxx}$ & - & $\mathrm{x}$ \\
\hline Clasto Lavrinha (*) & - & - & - & $\mathrm{xxx}$ & $\mathrm{xxx}$ & - & - & - & - & $x$ & - & $x x$ \\
\hline Alto Carrancas (*) & - & - & - & $x \times x x$ & $\mathrm{xxxx}$ & - & - & - & $x$ & $\mathrm{xx}$ & - & $x$ \\
\hline Datas de Cima (*) & $\mathrm{xxxx}$ & $\mathrm{xx}$ & $x$ & $\mathrm{xxxx}$ & $\mathrm{xxxx}$ & $\mathrm{xx}$ & $\mathrm{xx}$ & $\mathrm{xxx}$ & $\mathrm{xxx}$ & - & $\mathrm{xx}$ & $x$ \\
\hline Mugongo (*) & - & - & - & $\mathrm{xxx}$ & $\mathrm{xxx}$ & - & - & - & - & - & - & $x$ \\
\hline $\begin{array}{l}\text { Diamante Vermelho } \\
(*)\end{array}$ & - & - & - & $x x x$ & $\mathrm{xxx}$ & - & - & - & - & - & - & $x$ \\
\hline Brumadinho (*) & - & - & - & $\mathrm{xxx}$ & $\mathrm{xxxx}$ & - & - & - & $x$ & - & - & $\mathrm{x}$ \\
\hline Sopa (*) & - & - & - & $\mathrm{xxx}$ & $\mathrm{xxxx}$ & - & - & - & $x$ & - & - & $x$ \\
\hline Boa Vista (*) & - & - & - & $\mathrm{xxxx}$ & $\mathrm{xxx}$ & - & - & - & $\mathrm{x}$ & - & - & $\mathrm{x}$ \\
\hline Campo Sampaio (**) & - & - & - & $x \times x x$ & $\mathrm{xxx}$ & $\mathrm{xxx}$ & - & - & $\mathrm{xxx}$ & - & - & $\mathrm{x}$ \\
\hline Chalé (***) & - & - & - & $\mathrm{xxxx}$ & $\mathrm{xxxx}$ & - & - & - & - & - & - & $\mathrm{x}$ \\
\hline Pedra Rica (***) & - & $x$ & - & $\mathrm{xxxx}$ & $\mathrm{xxx}$ & - & - & - & $x$ & $\mathrm{xx}$ & - & $\mathrm{x}$ \\
\hline Batatal (***) & - & $\mathrm{xxx}$ & - & $\mathrm{xxxx}$ & $\mathrm{xxx}$ & - & - & - & $x$ & $\mathrm{xx}$ & - & $x$ \\
\hline
\end{tabular}

Espinhaço não foram realizados.

Supergrupo Espinhaço: Formação Grão Mogol Também integrando a megaseqüência proterozóica do Supergrupo Espinhaço em Minas Gerais, os conglomerados que afloram nos arredores de Grão Mogol, região do Espinhaço Central, foram inicialmente descritos como diamantíferos por Helmreichen (1846), tornando-se assim as primeiras rochas deste tipo reconhecidas em todo mundo. Moraes \& Guimarães (1930) e Moraes et al. (1937) sugeriram a correlação dessas rochas com a Formação Sopa descrita na região de Diamantina, no que foram acompanhados por estudos regionais posteriores, tais como os de Pflug (1965) e Uhlein (1991).

Durante a década de 1990, diversos trabalhos foram realizados pelos autores e equipe na região de Grão Mogol (Chaves 1997, Chaves et al. 1997, 1999), visando os principais aspectos estratigráficos e econômicos das rochas mineralizadas em questão. Destes estudos, resultou uma nova proposta estratigráfica, onde os conglomerados diamantíferos foram integrados a uma nova unidade, então proposta com a designação de Formação Grão Mogol (de idade mais nova que a Formação Sopa-Brumadinho), em sobreposição aos quartzitos finos definidos anteriormente por Karkunkel \& Karfunkel (1976) como Formação Resplandecente.

Os conglomerados da Formação Grão Mogol afloram em discordância angular e erosiva sobre a Formação Resplandecente, fato previamente evidenciado nas figuras mostradas $\mathrm{em}$ Moraes (1934 - pranchas 6 e 7). Os corpos são tabulares, com espessuras bastante constantes entre $2-3 \mathrm{~m}$. Os clastos são exclusivamente de quartzito fino e quartzo de veio, que aparecem interpenetrados com a matriz quartzítica também fina. As condições de sedimentação destas rochas ainda carecem de estudos detalhados, tendo já sido interpretadas como de placeres costeiros (Karfunkel \& Karfunkel 1976) ou fluviais (Chaves et al. 1999).

Supergrupo São Francisco: Grupo Macaúbas O Grupo Macaúbas, que compõe a base do Supergrupo São Francisco, 
foi depositado durante o Neoproterozóico (Karfunkel \& Hoppe 1988). Esta unidade foi de início designada por Moraes \& Guimarães (1930) na categoria de formação, quando foi correlacionada ao Conglomerado Sopa da região de Diamantina (anteriormente descrito), ambos compondo a "Série Lavras". Estes últimos autores, apesar de não verificarem em nenhum local contato direto entre as duas formações, consideraram a Formação Sopa como mais antiga por apresentar maior intensidade de metamorfismo. Somente com os estudos de Pflug (1965), a Formação Macaúbas foi designada como uma unidade independente, mais nova que a Formação Sopa c que as outras unidades que integram o Supergrupo Espinhaço. As litologias típicas do Grupo Macaúbas correspondem a metadiamictitos de matriz quartzítica fina, com clastos de tamanhos muito variados (até $>1 \mathrm{~m}$ de diâmetro), de múltiplos tipos litológicos e áreas de origem (quartzo, quartzitos, rochas gnáissicas, graníticas, vulcânicas e calcárias), e ainda diversos graus de arredondamento e esfericidade. A faciologia apresentada fez com que, desde sua descrição inicial, e em estudos detalhados posteriores, tais rochas fossem consideradas como de origem glacial (Moraes \& Guimarães 1930, Hettich 1977, Karfunkel \& Hoppe 1988).

A presença de diamantes nesses tilitos foi também uma proposição inicial de Moraes \& Guimarães (1930): "parece que no Rio Macahubas o diamante e o carbonado provêm, em grande parte, da desintegração dos conglomeratos da formação de mesmo nome...". Entre outros locais onde tais rochas teriam fornecido diamantes para sedimentos recentes, mencionaram alguns depósitos marginais ao Rio Jequitinhonha ao norte de Diamantina, e ainda os depósitos das encostas nordeste, norte, e noroeste da Serra do Cabral, onde estão localizadas as áreas diamantíferas de Buriti Grande, Francisco Dumont (ex-Conceição do Barreiro) e Jequitaí, respectivamente. Diversos outros autores têm realçado a importância dos metassedimentos glaciais Jequitaí-Macaúbas na distribuição regional dos diamantes não só no norte de Minas Gerais, como também em outras regiões brasileiras (Tompkins \& Gonzaga 1989, Gonzaga \& Tompkins 1991, Gonzaga \& Dardenne 1991).

Novos estudos realizados durante a última década, na região da Serra do Cabral (Karfunkel \& Chaves 1995, Chaves et al. 1998a, Bottino 2000), mostraram que os tilitos da Formação Jequitaí, pelo menos na área mencionada, não poderiam ser considerados como a fonte exclusiva dos diamantes encontrados nos depósitos sedimentares mais recentes. Entretanto, pela grande extensão das áreas de afloramento de tilitos e existência de depósitos diamantíferos em muitas destas áreas (Tompkins \& Gonzaga 1989, Gonzaga \& Tompkins 1990), parece haver poucas dúvidas sobre a existência pelo menos local de diamantes associados a tais rochas. Faltam ainda, porém, estudos mais detalhados de proveniência e pesquisa de minerais indicadores, assim como comparações entre as populações de diamantes das diversas áreas. Estudos econômicos também faltam completamente, apesar de que, pelo próprio ambiente de sedimentação a que tais depósitos se relacionam, os teores devam ser extremamente baixos e erráticos em todos os locais de ocorrência, para que compensem prospeç̧ão e pesquisa mais detalhada (Campos \& Gonzaga 1999).

Grupo Areado: Formação Abaeté Na borda oeste da Serra do Espinhaço, a Formação Abaeté, correspondente à porção basal do Grupo Areado, do Cretáceo Inferior, segundo GrossiSad et al. (1971), recobre parcialmente as serras do Cabral, da Água Fria e da Piedade, ao sul de Jequitaí, com espessuras variáveis entre 1,5 e 35m (Costa et al. 1998). Ela é constituída por um conglomerado clasto-sustentado, com seixos de quartzito e quartzo em matriz arenosa rarefeita, além de delgadas e incomuns intercalações de arenito. Tais conglomerados resultaram da tectônica vertical que provocou o modelamento da Serra do Espinhaço a partir do Jurássico, sendo depositados em canais fluviais derivados desta serra (Karfunkel \& Chaves 1994, 1995), ou ainda em leques aluviais localizados (Chaves et al. 1998a, Bottino 2000, Penha 2001), os quais são indicadores de atividade tectônica sin-sedimentar. Os estudos realizados na matriz desses conglomerados demonstraram a raridade de minerais não secundários (Tabela 3), sendo estes muito pequenos e arredondados (só observados na fração menor que $0,25 \mathrm{~mm}$ ), evidenciando longo transporte desde sua área-fonte.

Após a formulação da proposta de que tais rochas eram diamantíleras (Karfunkel \& Chaves 1994, Chaves et al. 1994), a Companhia Mineradora de Minas Gerais (COMIG), lançou

Tabela 3 - Freqüiência dos minerais pesados encontrados nos principais depósitos diamantíferos da região de Jequitaí (modificada de Bottino 2000). Percentuais utilizados: $x x x x=70-100 \%, x x x=20-70 \%, x x=I-20 \%, x=<1 \%$.

\begin{tabular}{|l|l|l|l|l|l|l|}
\hline \multicolumn{1}{|c|}{ Depósitos } & Água Fria & \multicolumn{1}{|c|}{ Boi Morto } & Urucum & \multicolumn{1}{c|}{ Panazeiro } & Coruja & Itaporé \\
\hline Almandina & - & $\mathrm{x}$ & $\mathrm{x}$ & - & $\mathrm{x}$ & $\mathrm{x}$ \\
\hline Anatásio & $\mathrm{x}$ & $\mathrm{x}$ & $\mathrm{x}$ & $\mathrm{x}$ & - & - \\
\hline Antofilita & - & - & $\mathrm{x}$ & - & - & - \\
\hline Cianita & $\mathrm{x}$ & - & - & $\mathrm{x}$ & - & $\mathrm{x}$ \\
\hline Estaurolita & - & $\mathrm{xx}$ & - & $\mathrm{xx}$ & - & - \\
\hline Fragmento laterítico & - & $\mathrm{xxxx}$ & $\mathrm{x} x \mathrm{xx}$ & $\mathrm{xxx}$ & $\mathrm{xxxx}$ & $\mathrm{xxxx}$ \\
\hline Ilmenita & - & - & - & $\mathrm{x}$ & - & $\mathrm{x}$ \\
\hline Leucita & - & - & - & $\mathrm{x}$ & - & - \\
\hline Limonita & - & - & $\mathrm{xxx}$ & - & $\mathrm{xx}$ & $\mathrm{xxx}$ \\
\hline Magnetita & $\mathrm{x}$ & $\mathrm{x}$ & $\mathrm{x}$ & $\mathrm{xx}$ & $\mathrm{x}$ & $\mathrm{x}$ \\
\hline Quartzo c/ óxido(s) & $\mathrm{x}$ & $\mathrm{xx}$ & $\mathrm{xx}$ & $\mathrm{xxx}$ & $\mathrm{xx}$ & $\mathrm{xx}$ \\
\hline Rutilo & $\mathrm{x}$ & $\mathrm{x}$ & $\mathrm{x}$ & $\mathrm{x}$ & $\mathrm{x}$ & $\mathrm{x}$ \\
\hline Turmalina preta & $\mathrm{x}$ & $\mathrm{x}$ & - & $\mathrm{x}$ & - & - \\
\hline Zircão & $\mathrm{x}$ & $\mathrm{x}$ & $\mathrm{x}$ & $\mathrm{x}$ & $\mathrm{x}$ & $\mathrm{x}$ \\
\hline
\end{tabular}


sobre elas na região de Várzea da Palma-Jequitaí, um extenso programa de prospecção e pesquisa, levando à cubagem milhões de toneladas de minério (Penha 2001). Apesar deste grande volume, provavelmente os teores são muito baixos para compensar uma lavra racional, tendo-se em vista depósitos semelhantes na África Ocidental (De Wit 1999), havendo reconcentração e conseqüente interesse apenas nos depósitos mais jovens.

Na borda leste do Espinhaço, Chaves \& Karfunkel (1997), reconheceram depósitos congêneres nas regiões de Senador Modestino Gonçalves e Grão Mogol. Seus aspectos são muito semelhantes aos conglomerados da Serra do Cabral e, pelo menos na primeira área, tais depósitos já foram objeto local de garimpagem.

Depósitos de coberturas lateritizadas in situ Uma importante fase de denudação e aplainamento do relevo recobrindo o Conglomerado Abaeté, gerando intensa lateritização, ocorreu durante o Terciário (Paleoceno-Mioceno?) em conseqüência da estabilidade tectônica pós-cretácica, produzindo uma couraça de espessura variável entre 1 e $30 \mathrm{~m}$. Este período, conhecido como Ciclo Sul-Americano (King 1956), levou à formação de longos chapadões de direção norte-sul nos interflúvios a leste e a oeste da Serra do Espinhaço, sustentando o relevo entre as cotas de 1050 e $1000 \mathrm{~m}$. Análises químicas por fluorescência de raios-X e plasma efetuadas nos sedimentos lateritizados de diversas áreas, assim como em locais onde o perfil laterítico é completo (Tabela 4), comprovaram o alto estágio de evolução dessas lateritas. Na região da Serra da Água Fria, sendo os conglomerados da Formação Abaeté possuidores de diamantes, conseqüentemente sua cobertura laterítica in situ também será mineralizada. No entanto, como se tratam de lateritas muito evoluídas, além dos esperados baixos teores, seu elevado grau de endurecimento inibe qualquer tentativa de prospecção diamantífera.

Depósitos de fanglomerados de borda serrana Nas porções marginais das serras do Espinhaço Meridional e Central (principalmente em sua borda oeste), do Cabral e da Água Fria, ocorrem sedimentos cenozóicos (Mioceno-Plioceno?), fanglomeráticos, com espessuras variáveis entre 0,5 e $3 \mathrm{~m}$, constituídos por seixos, blocos e matacões, na maior parte de quartzitos, em matriz síltica abundante (Chaves 1997, Chaves et al. 1994, 1998a). Em Grão Mogol, o "afinamento" da serra permitiu a formação de extensos depósitos deste tipo ao seu sopé, como na localidade de Matias Sanches. Na região de Francisco Dumont, onde pela primeira vez tal fácies foi reconhecida, no garimpo do Boi Morto, a gênese desses sedimentos foi atribuída pelos autores anteriormente citados, a um pos- sível soerguimento serrano ocorrido no final do Terciário.

De acordo com Bottino (2000), em Jequitaí-Francisco Dumont os depósitos fanglomeráticos foram desmembrados em duas fácies, "Boi Morto" e "Coruja", por suas diferentes posições topográficas e também estratigráficas. Em Jequitaí, os depósitos que tipificam a fácies Boi Morto ocorrem a leste da cidade, nas áreas de garimpo conhecidas como Lavrinha $\mathrm{e}$ Urucum. A mineralogia dos pesados desta fácies, verificada nos garimpos do Boi Morto e do Urucum, inclui abundante material originado no processo de lateritização tardio, além de granadas (Tabela 3), embora o próprio perfil encontre-se lateritizado pelo processo ocorrido a partir do Pleistoceno.

Depósitos de solos lateríticos Uma nova fase de lateritização regional caracteriza-se por afetar variavelmente as rochas e sedimentos pré-existentes entre cotas bastante diferentes na região da Serra do Espinhaço. Nas proximidades de Datas, depósitos deste tipo são conhecidos como "paçocas" pelos garimpeiros, ocorrendo próximos à cota de $1250 \mathrm{~m}$ com cerca de $1 \mathrm{~m}$ de espessura, derivando de lateritas pouco espessas desenvolvidas sobre os quartzitos e conglomerados da Formação Sopa-Brumadinho. Na região de Jequitaí, solos diamantíferos muito semelhantes desenvolvem-se entre 800 a $520 \mathrm{~m}$, onde podem ter espessuras desde centimétricas até um máximo de $3 \mathrm{~m}$, como observado no garimpo do Urucum (Bottino 2000, Penha 2001). O perfil de lateritização desta fase não é completamente evoluído, havendo ainda muita sílica e logo menor enriquecimento de ferro em relação às suas congêneres terciárias (Tabela 4). Ainda em Jequitaí, como tais lateritas "modernas" recobrem e/ou afetam sobremaneira os depósitos atribuídos ao Plioceno (fácies "Boi Morto") até a cobertura colúvio-eluvionar sub-recente, sugere-se para elas uma idade de desenvolvimento principal durante o Pleistoceno, em períodos mais quentes e úmidos dos intervalos interglaciais atuantes sobretudo nas latitudes continentais mais altas, embora provavelmente tenham afetado também as regiões serranas do Brasil Central (Chaves 1997, Karfunkel et al. 1998).

Depósitos de terraços altos Os terraços aluvionares altos, normalmente atribuídos ao final do Pleistoceno, ocorrem em níveis até $100 \mathrm{~m}$ superiores $\mathrm{em}$ relação a planície aluvionar atual dos rios, condicionados a atividades neotectônicas. Os garimpeiros designam tais depósitos como "grupiaras altas", estando os mais típicos e extensos localizados na margem esquerda do Rio Jequitinhonha, onde podem alcançar dezenas de quilômetros de extensão e até $2 \mathrm{~m}$ de espessura. Em Jequitaí, tais depósitos possuem pequeno porte porém são bastante comuns, podendo atingir até $4 \mathrm{~m}$ de espessura. Fora da Província do Espinhaço, nas cabeceiras do Rio São Francisco logo a

Tabela 4 - Análises químicas por fluorescência de raios-X dos óxidos de elementos maiores e menores (\% em peso) de sedimentos diamantíferos lateritizados, amostrados em três locais da Serra da Água Fria e nos garimpos da Lavrinha, Coruja e Itaporé, em Jequitaí(modificada de Bottino 2000).

\begin{tabular}{|c|l|l|l|l|l|l|l|l|l|l|l|l|}
\hline \multirow{2}{*}{ Tipo } & Local & $\mathrm{SiO}_{2}$ & $\mathrm{Al}_{2} \mathrm{O}_{3}$ & $\mathrm{Fe}_{2} \mathrm{O}_{3}$ & $\mathrm{TiO}_{2}$ & $\begin{array}{l}\mathrm{MnO} \\
(\%)\end{array}$ & $\mathrm{MgO}$ & $\mathrm{Na}_{2} \mathrm{O}$ & $\mathrm{K}_{2} \mathrm{O}$ & $\mathrm{P}_{2} \mathrm{O}_{5}$ & P.F. & TOT. \\
\hline \multirow{3}{*}{ Antiga } & Serra da & 40,0 & 21,6 & 15,8 & 1,7 & 0,7 & $<0,4$ & 0,2 & $<0,1$ & 0,3 & 17,1 & 97,7 \\
& Água Fria & 43,3 & 12,2 & 22,4 & 0,8 & 0,8 & $<0,4$ & 0,2 & $<0,1$ & 0,2 & 17,3 & 97,4 \\
& & 43,7 & 20,5 & 15,3 & 1,6 & 0,7 & $<0,4$ & 0,2 & $<0,1$ & 0,2 & 16,1 & 98,4 \\
\hline \multirow{3}{*}{ Moderna } & Lavrinha & 48,5 & 20,8 & 9,8 & 1,4 & 0,6 & 0,5 & 0,5 & $<0,1$ & 0,1 & 16,1 & 98,3 \\
& Coruja & 43,5 & 21,2 & 8,5 & 0,9 & 5,9 & 0,9 & 0,1 & $<0,1$ & 0,1 & 14,3 & 95,4 \\
& Itaporé & 56,1 & 15,4 & 9,9 & 0,9 & 1,0 & 0,5 & 0,1 & 1,2 & 0,2 & 16,5 & 101,8 \\
\hline
\end{tabular}


jusante da Cachoeira Casca d'Anta, município de Vargem Bonita, as principais atividades de lavra se associam a depósitos deste tipo. Ainda que em geral sejam bastante ricos, tais depósitos possuem uma lavra onerosa, devido às dificuldades normalmente encontradas para o abastecimento de água.

Depósitos de colúvios intra-serranos Durante o Holoceno "precoce", depósitos detríticos transportados recobriram as sequiências anteriormente descritas, constituindo sedimentos heterogêneos, compostos na base por um cascalho coluvionar grosso ("gorgulho" para os garimpeiros) formado por areias, grânulos e seixos, desde angulosos até bem arredondados e, no topo, por areias média a grossa, vermelhas, localmente com grânulos e seixos dispersos. A seqüência, localmente diamantífera, raramente ultrapassa $5 \mathrm{~m}$ de espessura, e o cascalho basal (em geral inferior a $1 \mathrm{~m}$ de espessura), nem sempre está presente. Na região de Diamantina, esses depósitos foram datados, por termoluminescência em quartzo, em @20.000 anos (Karfunkel et al. 1998). No garimpo do Urucum, em Jequitaí, a grande espessura do solo arenoso, vermelho muito forte, deu o nome ao local, embora o material preferencialmente lavrado seja o fanglomerado "Boi Morto", que aparece abaixo do cascalho basal ("gorgulho"). Segundo Chaves (1997), na região do Espinhaço essas coberturas foram formadas pelo transporte em enxurradas de material inconsolidado oriundo das áreas mais altas, após o clímax da última glaciação pleistocênica (Würm ou Winsconsin, no hemisfério norte).

Depósitos de lezírias As lezírias da região da Serra do Espinhaço, de idade recente ou sub-recente, ocorrem ao longo da planície aluvionar dos rios, sendo bastante importantes principalmente fora do espigão serrano, ou seja, quando os rios deixam sua fase juvenil (alto curso) e alcançam sua fase madura (médio curso). Tais depósitos são conhecidos como "grupiaras" pelos garimpeiros, possuindo em geral espessuras inferiores a $2 \mathrm{~m}$. A planície aluvionar do Rio Jequitinhonha, à jusante de Mendanha, é o exemplo mais notável deste tipo de depósito na região, possuindo uma largura que pode chegar a $2 \mathrm{~km}$, onde operam grandes dragas de alcatruzes (Dupont 1991, Fleischer 1991). O Rio Jequitaí, ao norte da Serra do Cabral, possui importantes depósitos de lezírias, praticamente virgens. No âmbito da Serra do Espinhaço, constituem exceções, ainda que restritas $(<100 \mathrm{~m})$ e na maior parte já esgotadas, as planícies aluvionares dos ribeirões Datas, Pardo Grande e Pardinho, pertencentes à bacia do Rio São Francisco.

Depósitos das calhas atuais dos rios De modo geral são diamantíferos os rios recentes que cortam alguma unidade mineralizada mais antiga. Assim sendo, praticamente todos os rios da região central serrana do Espinhaço possuem depósitos de maior ou menor porte, e a própria ocupação humana nesses locais foi condicionada a esse fator. No presente, porém, podese considerar que tais depósitos estejam exauridos pelo longo período de atividades de garimpagem (quase 300 anos). Em todos os locais onde se observam restos preservados deste material, a espessura do cascalho mineralizado varia entre 0,5 a $1,5 \mathrm{~m}$. No Rio Jequitaí, onde ainda ocorrem diversos setores com cascalhos virgens, eles são formados por areias, grânulos e seixos, em geral de quartzo e quartzito (com diamictitos subordinados) bem arredondados. Depósitos em marmitas são comuns quando o substrato rochoso é constituído pelos quartzitos do Supergrupo Espinhaço ou pelo Tilito Jequitaí, como a sul e a leste de Jequitaí. Tais depósitos já foram bastante garimpados, porém na atualidade a fiscalização ambiental tem limitado severamente esta prática.

A figura 2 apresenta, de modo esquemático, os principais tipos de depósitos contendo diamantes, relacionando os pipes kimberlíticos/lamproíticos (ainda desconhecidos), os conglomerados antigos (pré-cambrianos, dobrados) e seus diversos depósitos fanerozóicos derivados.

DISCUSSÕES SOBRE A RECICLAGEM DO DIAMANTE NO REGISTRO SEDIMENTAR O diamante, por suas propriedades físicas e químicas peculiares, talvez seja o mine-

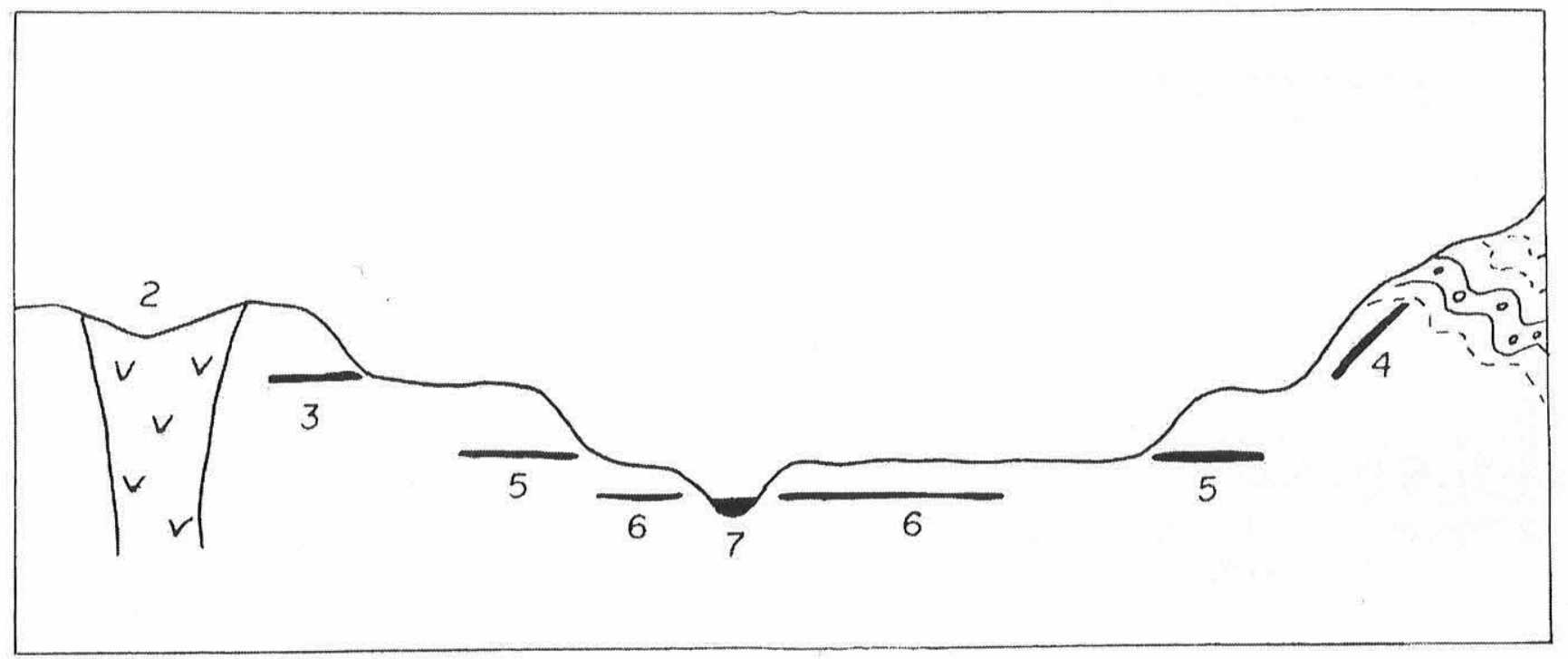

Figura 2 - Representação esquemática dos diferentes tipos de depósitos diamantíferos da Serra do Espinhaço e adjacências. 1-Conglomerados dobrados, pré-cambrianos, 2-Hipótética rocha fonte primária, erodida até suas raízes, 3-Conglomerados cretácicos, 4-Colúvios intra-serranos, 5-Terraços altos, 6-Lezírias (planícies aluvionares), 7-Calha atual do rio. 
ral mais resistente aos processos atuantes sobre a crosta terrestre. Tais características, permitem que este mineral seja continuamente reciclado na evolução do registro sedimentar, ocorrendo muitas vezes a grandes distâncias geográficas, ou mesmo no tempo geológico, de suas áreas fontes primárias (exemplos típicos são os depósitos diamantíferos em placeres marinhos na costa da Namíbia, sudoeste africano). Diversos estudos recentes têm considerado a existência de diamantes na região da Serra do Espinhaço como mais um forte argumento a favor desses múltiplos processos de reciclagem (e.g. Chaves 1997 , Chaves et al. 1994, 1998a,b, 1999, Karfunkel \& Chaves 1995, Karfunkel et al. 1996). De maneira análoga, no sul da África diversos autores também enfatizaram a resistência do diamante aos processos geológicos (e.g. Linari-Linholm 1973, Sutherland 1982, Turner \& Minter 1985).

Tais estudos na Serra do Espinhaço têm demonstrado que os depósitos diamantíferos podem ser relacionados a três longos períodos distintos de evolução geológica (Fig. 3). Um período magmático, Pré-Cambriano ( $\left.{ }^{3} 1,75 \mathrm{Ga}\right)$, cujo tempo de ocorrência ou área(s) exata(s) de emplacement permanece(m) como um enigma. Durante um segundo período, os diamantes foram depositados na porção basal da bacia Espinhaço, de idade paleo/mesoproterozóica (@1,75-1,70Ga). Ainda durante o PréCambriano, a glaciação continental verificada em diversas partes do mundo durante o Neoproterozóico, provavelmente contribuiu para a redistribuição dos diamantes de suas fontes primárias para uma parcela dos depósitos glaciogênicos. Um terceiro período ocorreu no Fanerozóico, quando, em conseqüência do soerguimento regional juro-cretácico, os conglomerados antigos foram erodidos e os diamantes redepositados no decorrer do Eocretáceo em sistemas fluviais entrelaçados, com fontes no espigão serrano recém-levantado do Espinhaço. Tais conglomerados são em geral anti-econômicos devido a cobertura laterítica espessa, desenvolvida no Terciário.

Durante o Neógeno, novos soerguimentos localizados permitiram a formação de fanglomerados nas bordas da Serra do Espinhaço e outras menores adjacentes. No decorrer do Quaternário, oscilações climáticas levaram à sedimentação dos depósitos coluvionares intra-serranos. Os diamantes desses depósitos são lavrados quando situados nas proximidades dos conglomerados pré-cambrianos e/ou cretácicos. Os depósitos aluvionares recentes e sub-recentes, apesar dos baixos teores

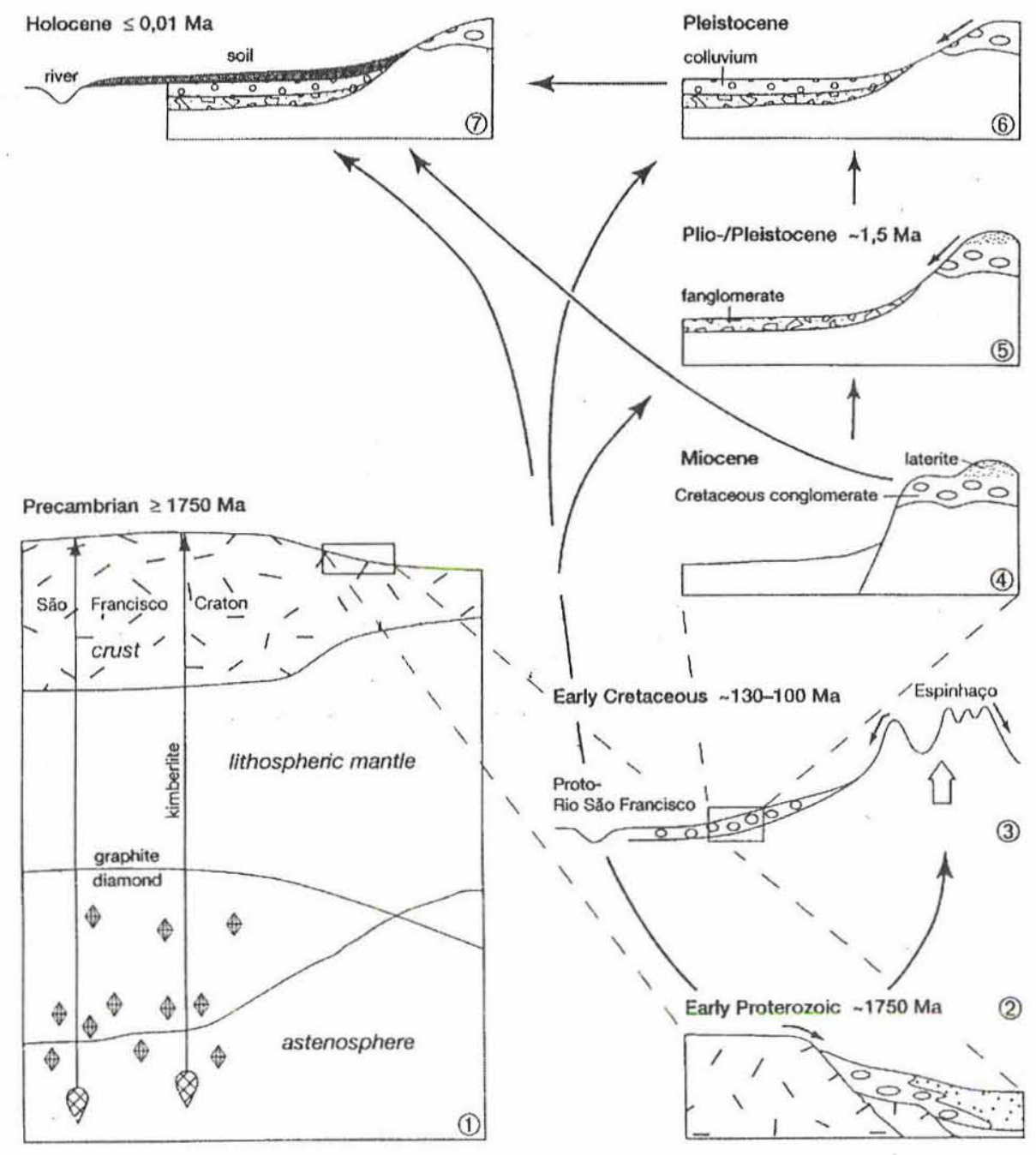

Figura 3 - Esquema hipotético de formação, evolução e distribuição dos depósitos diamantíferos em múltiplos estágios desde o Paleoproterozóico até o Recente. 
em diamante, representam atualmente as principais fontes do mineral, devido às imensas reservas existentes. As características mineralógicas dos diamantes, em combinação com os aspectos geológicos, refletem os diversos ciclos de retrabalhamento, indicando para eles uma área fonte extrabacia, provavelmente localizada no Cráton do São Francisco. Essas características são conseqüência da seleção natural que eliminou os diamantes de baixa qualidade durante a evolução do registro geológico (Chaves 1997, Chaves et al. 2001).

CONCLUSÃO Embora alguns autores advoguem a existência de rochas fontes primárias, intusivas na porção basal do Supergrupo Espinhaço, (e.g. Fleischer 1995, 1998, AlmeidaAbreu 1996), tais rochas não foram comprovadas até o presente momento. Com a descrição da tipologia dos depósitos diamantíferos secundários da Serra do Espinhaço e adjacências, pretendeu-se retratar a longa história de evolução geológica, com mais que 1,7 Ga, além de procurar exemplificar as dinâmicas envolvidas nesses processos. São encontrados depósitos formados em leques aluviais, fluviais, marinhos(?), fanglomeráticos e provavelmente também glaciais. A múltipla reciclagem dos depósitos ao longo desse intervalo de tempo está refletida diretamente nas características das populações de diamantes, o que os presentes autores têm procurado demonstrar em diversas ocasiões (e.g. Chaves 1997, Chaves et al. 1998b, 2001, Karfunkel et al. 1994, 1996).

Os variados estudos abrangendo os depósitos diamantíferos em questão tiveram quase sempre como objetivos descobrir possíveis fontes primárias - sem dúvidas uma meta fascinante em termos geológicos e "tentadora" em termos comerciais. Entretanto, deve ser lembrado que em dependência de condições morfológicas e climáticas, rochas ultrabásicas, como kimberlitos e lamproítos, podem ser erodidas em cerca de 60 milhões de anos até suas zonas de raízes. Assim sendo, a ocorrência de pipes pré-cambrianos mineralizados é raríssima, abrindo a larga possibilidade das mesmas no Espinhaço não existirem mais, ou então estarem encobertas por espessos sedimentos plataformais na área cratônica. As amplas discussões a respeito não levaram a resultados conclusivos e permanecem hipotéticas. Desta maneira, a rocha primária dos diversos depósitos diamantíferos (secundários) no Espinhaço pode ser considerada, até o presente, como enigmática.

Agradecimentos Os autores expressam seus agradecimentos aos projetos de pesquisa apoiados pela FAPEMIG e CNPq no âmbito da Serra do Espinhaço e a dois revisores anônimos da RBG pelas sugestões ao manuscrito.

\section{Referências}

Almeida-Abreu P.A. 1996. O caminho das pedras. Geonomos, 4:77-93.

Bottino E.C.C. 2000. Tipologia, aspectos mineralógicos e econômicos dos depósitos diamantíferos das regiōes de Jequitaí e Francisco Dumont (MG). Belo Horizonte, 195p. (Dissertação de Mestrado, IGC/UFMG).

Campos J.E.G. \& Gonzaga G.M. 1999. O transporte de diamantes por sistemas fluviais a longas distâncias: uma visão crítica. Revista Brasileira de Geociências, 29:113-118.

Chaves M.L.S.C. 1997. Geologia e mineralogia do diamante da Serra do Espinhaço em Minas Gerais. São Paulo, 289p. (Tese de Doutoramento, IG/ USP).

Chaves M.L.S.C. \& Uhlein A. 1991. Depósitos diamantíferos da região do Alto/ Médio Rio Jequitinhonha, Minas Gerais. In: Schobbenhaus C. Queiroz. E.T., Coelho C.E.S., eds., Principais Depósitos Minerais do Brasil, vol.IVA. Brasília, DNPM/CPRM, p.117-138.

Chaves M.L.S.C. \& Svisero D.P. 1993. Características geológicas e origem dos conglomerados diamantíferos das regiões de Diamantina (Mesoproterozóico) e de Romaria (Cretáceo Superior), Minas Gerais. Boletim IG-USP, Série Científica, 24:49-57.

Chaves M.L.S.C. \& Karfunkel J. 1997. A protobacia do Rio Jequitinhonha (Minas Gerais) durante o Cretáceo Inferior e seu potencial diamantífero. Geociências, 16:191-201.

Chaves M.L.S.C., Dupont H., Karfunkel J., Svisero D.P.1993, Depósitos diamantíferos de Minas Gerais: uma revisão. In: Simpósio Brasileiro de Geologia do Diamante, I, Cuiabá, 1993. Anais... Cuiabá, UFMT/SBG, p.79-100.

Chaves M.L.S.C., Karfunkel J., Pena J.L.M. 1994. Depósitos coluviais diamantíferos da região de Jequitaí-Francisco Dumont, Minas Gerais. In: Congresso Brasileiro de Geologia, 28, Balneário Camboriú, 1994. Boletim de Resumos Expandidos... Balneário Camboriú, SBG, v. I, p.189-190.

Chaves M.L.S.C., Karfunkel J., Wegner R. 1997. Diamantvorkommen von Grão Mogol - geologische und gemmologische Untersuchungen in Minas Gerais, Brasilien. Geowissenschaften, 15:73-78.

Chaves M.L.S.C., Karfunkel J., Svisero D.P. 1998a. Lower cretaceous conglomerates in the southern São Francisco basin, Minas Gerais: a proposed model for the redistribution of ancient diamonds to cenozoic colluvial-alluvial deposits. Anais da Academia brasileira de Ciências,
70:477-490.

Chaves M.L.S.C., Svisero D.P., Karfunkel J. 1998b. Sobre a problemática da origem do diamante na Serra do Espinhaço (Minas Gerais): um enfoque mineralógico. Revista Brasileira de Geociências, 28:285-294.

Chaves M.L.S.C., Karfunkel J., Addad J. 1999. Geologia da região diamantífera de Grão Mogol, Minas Gerais. Geocências, 18:129-155.

Chaves M.L.S.C., Karfunkel J., Hoppe A., Hoover D.B. 2001. Diamonds from the Espinhaço Range (Minas Gerais, Brazil) aind their redistribution through the geologic record. Journal of South American Earth Sciences, 14:277289.

Costa K.V., Penha U.C., Gonzaga G.M. 1998. Dados preliminares sobre as rochas cretáceas da região de Jequitaí, MG. In: Congresso Brasileiro de Geologia, 40, Belo Horizonte, 1998. Anais... Belo Horizonte, SBG, p.274.

De Wit M.C.J. 1999. Post-gondwana drainage and the development of diamond placers in Western South Africa. Economic Geology, 94:721-740.

Dossin I.A., Dossin T.M., Chaves M.L.S.C. 1990. Compartimentação estratigráfica do Supergrupo Espinhaço em Minas Gerais - os grupos Diamantina e Conselheiro Mata. Revista Brasileira de Geociências, 20:178-186.

Draper D. 1920. The high level diamond-bearing breccias of Diamantina, Brazil. Transactions of Geological Society of South Africa, 23:43-51.

Dupont H. 1991. Jazida aluvionar de diamante do Rio Jequitinhonha em Minas Gerais. In: Schobbenhaus C, Queiroz E.T., Coelho C.E.S., eds., Principais Depósitos Minerais do Brasil, vol.IV-A. Brasília, DNPM/CPRM, p.139. 148.

Dussin I.A. \& Dussin T.M. 1995. Supergrupo Espinhaço: modelo de evolução geodinâmica. Geonomos, 3:19-26.

Fleischer R. 1991. The Domingas diamond project. Belo Horizonte, Mineração Rio Novo, 19p.

Fleischer R. 1995. Prospeç̧ão e economia do diamante da Serra do Espinhaço. Geonomos, 3:27-30.

Fleischer R. 1998. A rift model for the sedimentary diamond deposits of Brazil. Mineralium Deposita, 33:238-254.

Fogaça A.C.C. \& Alıneida-Abreu P.A. 1982. Depósitos de planícies de marés na Formação Sopa-Brumadinho (Proterozóico Inferior), Cordilheira do 
Espinhaço, Estado de Minas Gerais, Brasil. In: Congresso Latinoamericano de Geologia, 5, Buenos Aires, 1982. Actas... Buenos Aires, v.2, p.373-388.

Garcia A.J.V. \& Uhlein A. 1987. Sistemas deposicionais do Supergrupo Espinhaço na região de Diamantina (MG). In: Simpósio sobre sistemas deposicionais do Pré-Cambriano, 1, Ouro Preto, 1987. Anais... Ouro Preto, SBG, p.113-136.

Gonzaga G.M. \& Tompkins L. 1990. Geologia do diamante. In: Schobbenhaus C, Queiroz E.T., Coelho C.E.S., eds., Principais Depósitos Minerais do Brasil, vol.IV-A. Brasília, DNPM/CPRM, p.53-116.

Gonzaga, G.M. \& Dardenne, M.A. 1991. The Jequitaí Glaciation and the dispersión of diamonds during Upper Proterozoic. In: International Kimberlite Conference, 5, Araxá, 1991. Field Guide Book... Araxá, CPRM, p.89-93

Grossi-Sad J.H., Cardoso R.N., Costa M.T. 1971. Formações cretácicas em Minas Gerais: uma revisão. Revista Brasileira de Geociências, 1:2-13.

Helmreichen V. 1846. Über das Geognostische Vorkommen der Diamanten und ihre Gewinnungs-methoden auf Serra do Grão Mogor. Wien, Braunmüller \& Seidel, 74p.

Hettich M. 1977. A glaciação proterozóica no centro-norte de Minas Gerais. Revista Brasileira de Geociências, 7:87-101.

Karfunkel B. \& Karfunkel J. 1976. Geologia da Serra do Espinhaço no norte de Minas Gerais (Itacambira-Botumirim). In: Congresso Brasileiro de Geologia, 29, Ouro Preto, 1976. Anais... Ouro Preto, SBG, v.2, p. 169-178.

Karfunkel, J. \& Hoppe A. 1988. Late Proterozoic glaciation in central-east Brazil: synthesis and model. Palaeogeography, Palaeoclimatology, Palaeoecology, $65: 1-21$.

Karfunkel J. \& Chaves M.L.S.C. 1994. Conglomerados cretácicos da Serra do Cabral, Minas Gerais, e sua possível relação com os diamantes aluvionares da região. In: Simpósio sobre o Cretáceo do Brasil, 3, Rio Claro, 1994. Boletim do... Rio Claro, UNESP, p.197-199.

Karfunkel J. \& Chaves M.L.S.C. 1995. Conglomerados cretácicos da Serra do Cabral, Minas Gerais: um modelo para a redistribuição coluvio-aluvionar dos diamantes do Médio São Francisco. Geociências, 14:59-72.

Karfunkel J., Chaves M.L.S.C., Svisero D.P., Meyer H.O.A. 1994. Diamonds from Minas Gerais, Brazil: an update on sources, origin and production. International Geology Review, 36:1019-1032.

Karfunkel J., Chaves M.L.S.C., Banko A., Hoppe A. 1996. Diamanten des Espinhaço-Gebirges, (Minas Gerais, Brasilien): Gemmologische und ökonomische Folgen geologischer Geschichte. Zeitschrift der Deutschen Gemmologischen Gesellschaft, 45:113-128.

Karfunkel J., Chaves M.L.S.C., Banko A., Hoover D.B. 1998. Colluvial diamond and quartz deposits from the Espinhaço Range (MG): genesis and economic importance. In: Congresso Brasileiro de Geologia, 40, Belo Horizonte, 1998. Anais... Belo Horizonte, SBG, p.272.

Kerr P.F. 1941. Nota de campo sobre a ocorrência de diamante no Distrito de Diamantina. Mineração Metalurgia, 4:54-63.

King, L.C. 1956. Geomorfologia do Brasil Oriental. Revista Brasileira de Geografia, 18:1-147.

Linari-Linholm A.A. 1973. The occurrence, mining, and recovery of diamonds. London, De Beers Consolited Mines, 44p.
Martins-Neto M.A. 1998. O Supergrupo Espinhaço em Minas Gerais: registro de uma bacia rifte-sag do Paleo/Mesoproterozóico. Revista Brasileira de Geociências, 28:151-168.

Moraes L.J. 1934. Depósitos diamantíferos no norte do Estado de Minas Gerais. Rio de Janeiro, DNPM/SFPM, 61p. (Boletim 3).

Moraes L.J. \& Guimarães D. 1930. Geologia da região diamantífera do norte de Minas Gerais. Anais da Academia Brasileira de Ciências, 2:153-186.

Moraes L.J., Barbosa O., Lisboa J.M.A., Lacourt F., Guimarães D. 1937. Geologia Econômica do norte de Minas Gerais. Rio de Janeiro, DNPM/SFPM, 191p. (Boletim 19).

Penha U.C. 2001. Geologia dos conglomerados da Serra da Água Fria e dos depósitos diamantíferos de Jequitaí, MG. Rio Claro, CD-ROM (Tese de Doutoramento, IGCE/UNESP).

Pflug R. 1965. A geologia da parte meridional da Serra do Espinhaço e zonas adjacentes, Minas Gerais. Rio de Janeiro, DNPM/DGM, 55p. (Boletim 226).

Pflug R. 1968. Observações sobre a estratigrafia da Série Minas na região de Diamantina, Minas Gerais. Rio de Janeiro, DNPM/DGM, 20p. (Notas Preliminares e Estudos 142).

Schobbenhaus C. 1993. Das Mittlere Proterozoikum Brasiliens mit besonderer Berücksichtigung des zentralen Ostens: Eine Revision. Freiburg, 166p. (PhD Thesis, University of Freiburg, Germany).

Schöll W.U. \& Fogaça A.C.C. 1979. Estratigrafia da Serra do Espinhaço na região de Diamantina (MG). In: Simpósio de Geologia de Minas Gerais, I, Diamantina, 1979. Atas... Diamantina, SBG-MG, p.55-73.

Silva R.R. 1995. Sequence stratigraphy and depositional systems of the Lower Espinhaço Supergroup in the area between Diamantina and Gouveia, Minas Gerais, Brazil. Freiburg, 145p. (PhD Thesis, Albert-Ludwigs Universität, Germany).

Sutherland D.G. 1982 The transport and sorting of diamonds by fluvial and marine processes. Economic Geology, 77:1613-1620.

Tompkins L.A. \& Gonzaga G.M. 1989. Diamonds in Brazil and a proposed model for the origin and distribution of diamonds in the Coromandel region, Minas Gerais, Brazil. Economic Geology, 84:591-602.

Turner B.R. \& Minter W.E.L. 1985. Diamond-bearing upper Karoo fluvial sediments in NE Swaziland. Journal of Geologic Society of London, 142:765-776.

Uhlein A. 1991. Transição craton-faixa dobrada: um exemplo do Cráton do São Francisco e da Faixa Araçuaí (Ciclo Brasiliano) no Estado de Minas Gerais. Aspectos estratigráficos e estruturais. São Paulo, 295p. (Tese de Doutoramento, IG/Univ. de São Paulo).

Uhlein A., Trompette R., Egydio-Silva M.1995. Rifteamentos superpostos e tectônica de inversão na borda sudeste do Cráton do São Francisco. Geonomos, 3:99-107.

Uhlein A.\& Chaves M.L.S.C. 2001. O Supergrupo Espinhaço em Minas Gerais e Bahia: correlações estratigráficas, conglomerados diamantíferos e evolução geodinâmica. Revista Brasileira de Geociências (submetido).

Manuscrito A-1295

Recebido em 21 de novembro de 2001

Revisão dos autores em 10 de dezembro de 2001 Revisão aceita em 12 de dezembro de 2001 